\title{
DEVELOPMENT OF NOVEL CORROSION RESISTANT ELECTROLESS NI-P COMPOSITE COATINGS FOR PIPELINE STEEL
}

\author{
Omar Chaar $^{2}$, George Jarjoura*1, Zoheir Farhat ${ }^{1}$ and Rami Nader ${ }^{2}$ \\ ${ }^{1}$ Department of Mechanical Engineering, Dalhousie University, Halifax, NS, Canada \\ B3J 2 X4. \\ ${ }^{2}$ Department of Chemical Engineering, Lebanense University, Tripoli, Lebanon. \\ *Corresponding author: George Jarjoura \\ george.jarjoura@dal.ca
}

(Received July 2017 - Accepted April 2019)

\begin{abstract}
Chaar, O. Jarjoura, G. Farhat, Z. and Nader, R. 2019. Development of novel corrosion resistant electroless NI-P composite coatings for pipeline steel. Lebanese Science Journal. 20(2): 262-271.

In this research, coatings with various particles contents will be co-deposited within Ni-P deposits on AISI 1012 steel samples by electroless coating process. As a result, structural changes were evaluated, surface and cross-section morphology of composite deposits have been investigated by scanning electron microscopy (SEM), volumetric percentage of co-deposited particles have been determined using EDS analysis system, corrosion resistance of various EN coatings and current density were studied through potentiodynamic polarization, and mechanical properties were evaluated using wear and nano-indentation tests. The results showed that Alumina can give the best compromise between surface smoothness and deposition rate, Titanium can reach the highest levels of volumetric incorporation whereas Carbon can improve further lubrication effect on wear action, finally hardness and corrosion behavior had the best results with the existence of Alumina.
\end{abstract}

Keywords: Electroless nickel, Alumina, Carbon, Titanium, Composite coating.

\section{INTRODUCTION}

The process of electroless nickel plating is an autocatalytic chemical reduction. Such reaction doesn't need an electric current in order to manufacture composite coatings around the object. EN techniques uses a chemical bath to deposit a nickel/phosphorous 
layer onto the object surface either it's conducted or not. This process provides high resistance against wear and corrosion and uniform nickel coating for sophisticated objects.

In this research, coatings with various particles contents will be co-deposited within Ni-P deposits on AISI 1012 steel samples for 1h30min [1]. As a result, various types of composite electroless nickel-phosphorus (EN) coatings, namely, with Carbon, Alumina \& Titanium will be created. Once coated, many studies will be operated and will rely on different evaluations: physical ones for surface microscopic, electrochemical for content and corrosion resistance and mechanical through Nano-indentation and wear tests to obtain hardness and Young's modulus. Finally, these results will be compared to show the effect of these particles on coating properties.

Table 1. Experimental conditions for electroless plating [2], [3].

\begin{tabular}{|l|l|l|l|l|}
\hline $\mathrm{pH}$ & Temperature & $\begin{array}{l}\text { Carbon } \\
\text { nanotubes }\end{array}$ & Alumina & Titanium \\
\hline $4.6+$ or -0.1 & $89+$ or $-1^{\circ} \mathrm{C}$ & $0.02 \mathrm{~g} / 1$ & $7 \mathrm{~g} / 1$ & $5 \mathrm{~g} / 1$ \\
\hline
\end{tabular}

\section{METHODOLOGY}

As a substrate, AISI1012 samples were used. Disk with dimensions of $15 \mathrm{~mm}$ radius and $6 \mathrm{~mm}$ thickness was grinded through 240, 320, 400, 600 silicon carbides (SiC) abrasive papers, then polished using $1 \mu \mathrm{m}$ gamma diamond paste. The purpose of grinding was to clean the surface and remove saw marks. Polishing was done in purpose to examine the microstructure. After polishing, the surface of the sample seemed like a mirror. It must be well cleaned with water and dried immediately to prevent any corrosion marks. Figure 1 shows the aspect of the samples before and after grinding/polishing.

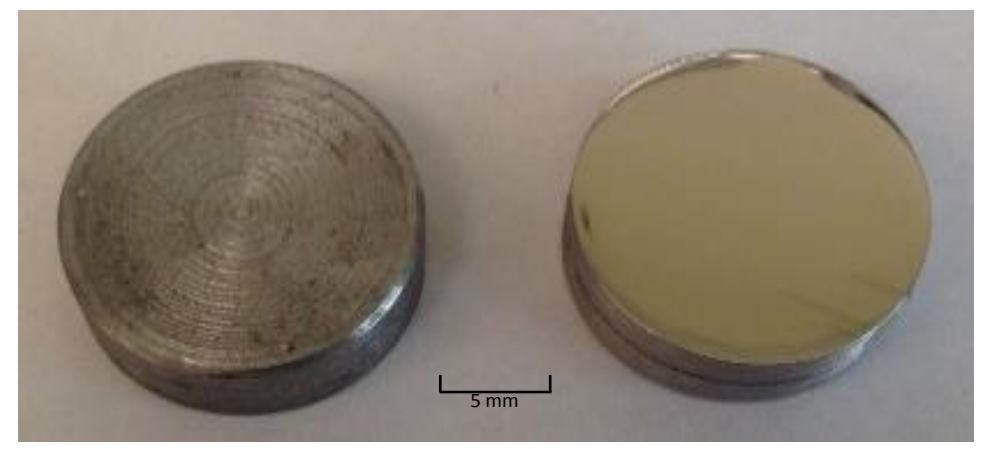

Figure 1. AISI 1018 steel samples before and after grinding/polishing. 
Table 2. Chemical composition of AISI1012 in wt. \%.

\begin{tabular}{|l|l|l|l|l|}
\hline $\begin{array}{l}\text { Manganese, } \\
\text { Mn }\end{array}$ & Carbon, C & Sulfur, S & Phosphorous, P & Iron, Fe \\
\hline $0.60-0.90$ & $015-0.20$ & $0.05 \max$ & $0.04 \max$ & Balance \\
\hline
\end{tabular}

Preparation procedure of nickel phosphorous coating (Preparation of substrates)

Pre-treatment process: The sample was dipped in Alkaline medium $(7<\mathrm{pH}<9)$ at $80^{\circ} \mathrm{C}$ for 5 minutes, and then rinsed with distilled water. Next step, the sample was dipped into a sulfuric acid $(15 \% \mathrm{v} / \mathrm{v})$ for $15 \mathrm{~s}$. After rinsing with distilled water, the pre-treatment phase is finally done [4] and the sample can be dipped into the Ni-P bath at $89^{\circ} \mathrm{C}$ for 90 minutes to obtain pure Ni-P coating.

Preparation procedure of composite coatings (Preparation of plating bath)

In the case of composite coating, after achieving the pre-treatment phase, the samples were coated for 30 minutes in pure Ni-P solution, after this step, the sample was dipped in another Ni-P bath that contains the related particles (Carbon, Alumina or Titanium) for $90 \mathrm{~min}$.

\section{Experimental details}

\section{Microscopic Evaluation}

Starting with the microscopic evaluation, results in table 3 showed the existence of these particles but with different percentage, $4.88 \%$ for Ni-P-C, $2.73 \%$ for Ni-P-Al2O3 and $26.18 \%$ for Ni-P-Ti. These numbers may not prove the superiority of coating over the other, yet it proves the incorporation of these particles in different amounts. The difference in coating surface can be seen in figure 2 as well, Titanium coated substrate is represented in rough dusky surface whereas Carbon Alumina particle presents smooth and brighter surface.

Table 3. Particles incorporation for different Ni-P baths.

\begin{tabular}{|l|l|}
\hline Coating & Particles incorporation (C-Al-Ti) \\
\hline Ni-P-C & $4.88 \%$ \\
\hline $\begin{array}{l}\text { Ni-P- } \\
\text { Al2O3 }\end{array}$ & $2.73 \%$ \\
\hline Ni-P-Ti & $26.18 \%$ \\
\hline
\end{tabular}




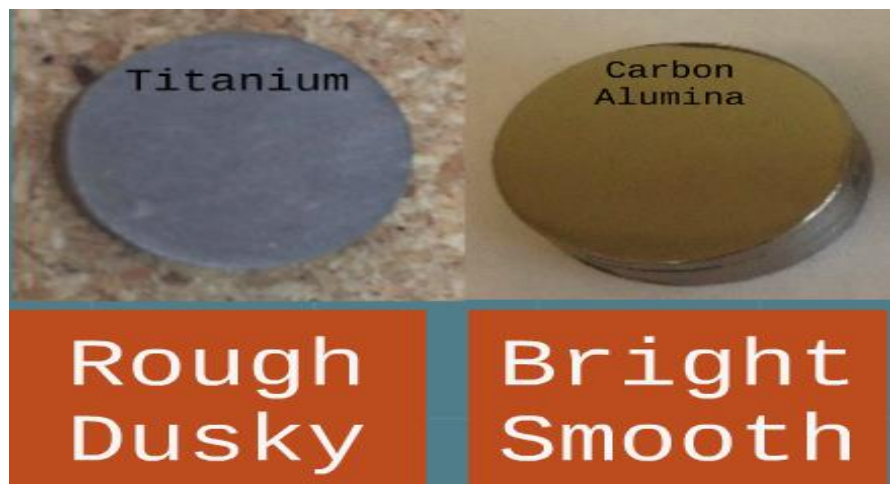

Figure 2. The different coating surface when using Carbon and Titanium particles.

\section{Physical Evaluation}

Studying the physical properties can give a better idea of coating surface and thickness. Results showed that Titanium had rough and dusky surface, whereas carbon and alumina obtained smooth and bright surface. In order to know the thickness of this coat, sample is cut in half, polished and observed through microscope, it was obvious that samples do not have the same thickness even though they had the same time in the solution cell. This can verify that each kind of particles can effect on deposition rate. As it's seen in Table 4, titanium has the highest deposition rate [5] with $20 \mu / \mathrm{s}$, but it doesn't mean that it has the best physical properties due to the rough surface that degrades its quality, for this reason we assume that alumina with $11.33 \mu \mathrm{m} / \mathrm{h}$ as deposition rate has the best physical properties with bright and smooth surface and high deposition rate.

Table 4. Deposition rate for different Ni-P baths.

\begin{tabular}{|l|l|}
\hline Compostite Coating With & Depositon Rate $(\mu \mathrm{m} / \mathrm{h})$ \\
\hline Carbon nanotubes 0.02g. & $4 \mu \mathrm{m} / \mathrm{h}$ \\
\hline Carbon nanotubes 0.05g. & $3 \mu \mathrm{m} / \mathrm{h}$ \\
\hline Alumina 7g. & $11.33 \mu \mathrm{m} / \mathrm{h}$ \\
\hline Titanium 5g. & $20 \mu \mathrm{m} / \mathrm{h}$ \\
\hline
\end{tabular}

\section{Corrosion tests and polarization measurements}

Polarization resistance tests were used to obtain the corrosion rates. The corrosion performance of Ni-P, Ni-P Carbon and Ni-P-Alumina plating in 3.5 wt. \% aqueous solution were assessed by potentiodynamic polarization curve and cyclic polarization in an traditional electrochemical cell. 
We used 3 different electrodes to run those experiments. The working electrode, the reference electrode (saturated calomel electrode) and the auxiliary electrode (carbon wire) used as counter electrode. The reference electrode had to be very close to the sample in order to minimise any error. The electrochemical measurements and potentiodynamic data were analyzed using a commercial computer package using the Tafel extrapolation to calculate the corrosion rate of the tested samples. It involves the extrapolation of corrosion current density icorr and corrosion potential Ecorr from the Tafel curve.

The icorr and Ecorr are extrapolated at the intersection between tangential slopes of the anodic and cathodic curves. For the present study the corrosion potentials and the corrosion current densities were estimated by using instantaneous Tafel-type fit CorrWare corrosion analysis software.

Calculation of the corrosion rate:

$C R=\frac{3.27 \times 10^{-3} \times i c o r r \times E W}{D}[6]$

$C R$ (corrosion rate): $\mathrm{mm} /$ year

icorr (corrosion current): $\mu \mathrm{A} / \mathrm{cm} 2$

$D$ (density) $=7.87 \mathrm{~g} / \mathrm{cm} 3$

$E W($ Equivalent Weight $)=27.71$

As mentioned above, the main parameter that we are interested in is the corrosion current icorr which will affect directly the corrosion rate. The results below that concern to the pure Ni-P coating can be seen in figure 3 .

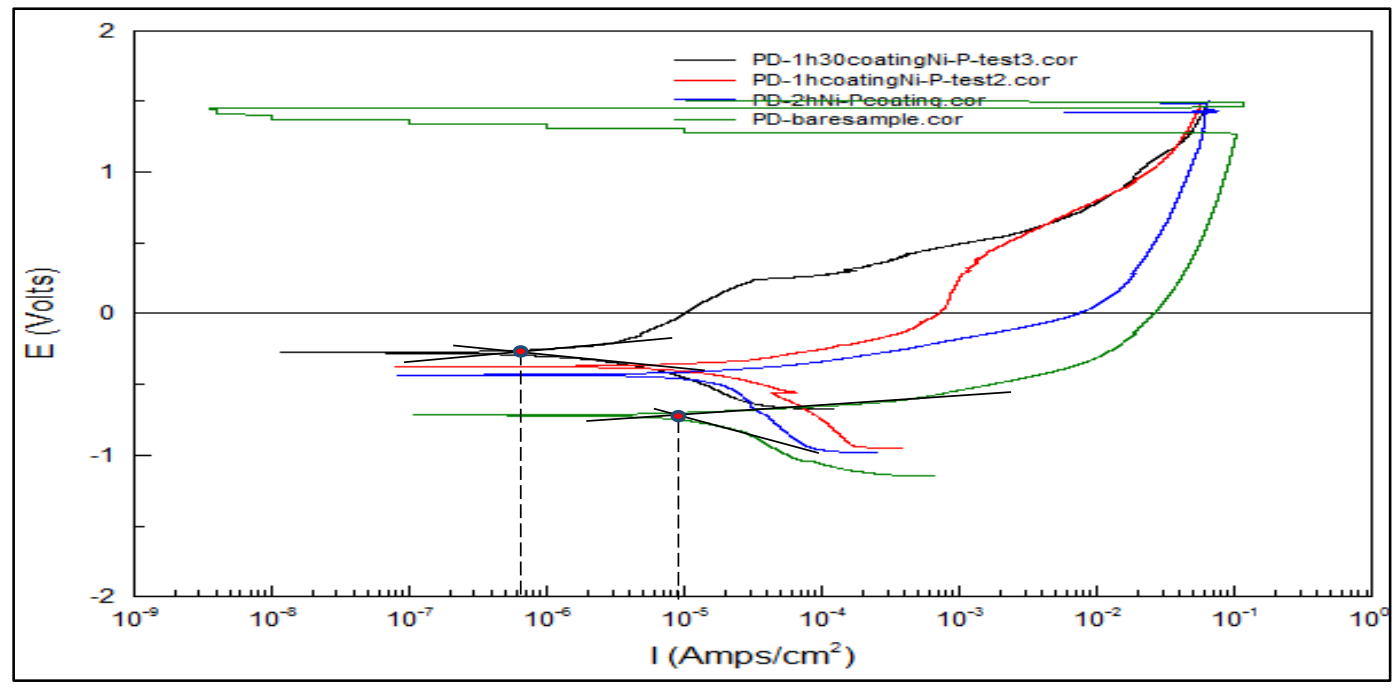

Figure 3. Potentiodynamic Polarization of 1 bare sample and different Ni-P coating samples. 
As Shown in Table 5, corrosion current for bare sample was $9.5 \mu \mathrm{A} / \mathrm{cm} 2$, it decreased slightly after 1-hour time of coating, but after $1 \mathrm{~h} 30 \mathrm{~min}$, corrosion current dropped to reach only $0.55 \mu \mathrm{A} / \mathrm{cm} 2$. Whereas in the case of 2 hours' time of coating corrosion current tend to increase again and reach $9 \mu \mathrm{A} / \mathrm{cm} 2$.

Table 5. Pure Ni-P Corrosion resistance with respect to time of coating.

\begin{tabular}{|l|l|l|l|l|}
\hline Type of coating & icorr $(\boldsymbol{\mu A A} / \mathbf{c m} 2)$ & Icorr $(\boldsymbol{\mu A})$ & $\mathbf{C R}(\mathbf{m m} / \mathbf{y r})$ & MR $(\mathbf{g} / \mathbf{m} 2 \mathbf{d})$ \\
\hline Ni-P Carbon $(0.02 \mathrm{~g} / \mathrm{L})$ & 10 & 7.824 & 0.1148 & 2.478 \\
\hline Ni-P Carbon $(0.05 \mathrm{~g} / \mathrm{L})$ & 8.49 & 6.66 & 0.097 & 2.105 \\
\hline Ni-P Alumina $(7 \mathrm{~g} / \mathrm{L})$ & 4.69 & 3.68 & 0.053 & 1.134 \\
\hline
\end{tabular}

In table 6, composite Ni-P coating shows dissimilar corrosion current, as for carbon $0.05 \mathrm{~g} / \mathrm{L}$ and $0.02 \mathrm{~g} / \mathrm{L}$, conversly for Alumina where corrosion current dropped to the half to show $4.69 \mu \mathrm{A} / \mathrm{cm} 2$.

Table 6. Composite Ni-P Corrosion resistance with respect to time.

\begin{tabular}{|l|l|l|l|l|l|}
\hline Type of coating & Time of coating & icorr $(\boldsymbol{\mu A} \mathbf{A} / \mathbf{c m} 2)$ & Icorr $(\boldsymbol{\mu A})$ & CR $(\mathbf{m m} / \mathbf{y r})$. & MR $(\mathbf{g} / \mathbf{m} 2 d)$ \\
\hline Bare & 0 & 9.5 & 12.14 & 0.109 & 2.355 \\
\hline Ni-P & hh & 9 & 11.5 & 0.103 & 2.223 \\
\hline Ni-P & 1h30 & 0.55 & 0.6985 & 0.00631 & 0.1363 \\
\hline Ni-P & 2h & 9 & 11.5 & 0.103 & 2.223 \\
\hline
\end{tabular}

Table 5 and Table 6 can be summarized in the diagram of figure 4, where a comparison chart shows the lead of Ni-P over other Ni-P composite samples with the exception of Ni-P-Ti sample.

\section{Mechanical Properties}

\section{Wear tests}

Tests are used for quality control function such as thickness, porosity, adhesion, strength, hardness, ductility, chemical composition, stress and wear resistance. One of the simplest ways of measuring wear is based on weight loss during and after a test. For our experiment, the objectives of the wear test were:

- Gain an understanding of the wear process.

- Determine the weight loss with the different loads applied,

- Get the coefficient of friction versus the load. 


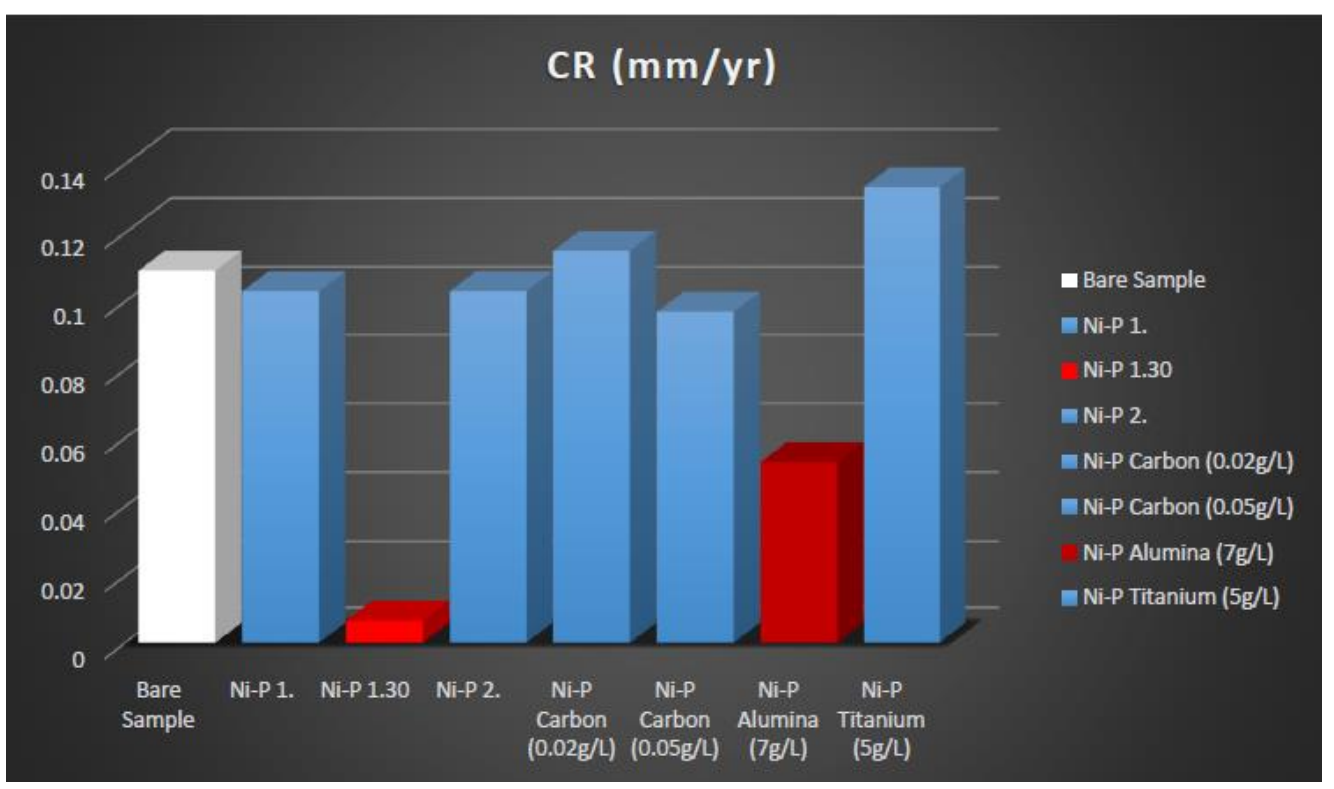

\section{Figure 4. Comparison chart showing the lead of Ni-P 1.30 over other Ni-P composite samples.}

During the test, a tungsten carbide ball with a diameter of $5.3 \mathrm{~mm}$ was used as a counter-face material. The ball slides against a flat pre-weighed specimen in a linear, back and forth motion. The ball is mounted inside a ball holder which is attached to a load sensor for controlling and recording forces. The parameters, tangential load (Fx), normal load $(\mathrm{Fz})$, wear track depth $(\mathrm{Z})$ are continuously monitored during the test. Different loads were applied between $4 \mathrm{~N}$ and $10 \mathrm{~N}$ to all the samples to compare the weight loss and the deepness of the tracks. The frequency applied was $4 \mathrm{~Hz}$ and the time was 10 minutes. Before and after wear test, the specimen is weighted with an electronic balance.

The coefficient of friction (COF) describes the ratio of the force of friction between two solid surfaces and the force pressing them together. The value is usually between 0 and 1 . A value of 0 means there is no friction at all between the objects and a value of 1 means the frictional force is equal to the normal force. Frictional resistance to the relative motion of two solid objects is usually proportional to the force which presses the surface together as well as the roughness of the surfaces. The frictional resistance is usually affected by the normal force to the surface which is, most of the time, equal and opposite to the weight of the object.

The COF is plotted as a function of different loads and different coating. As shown in Figure 5, The friction curve shows that the COF of the Ni-P-Carbon coating $(0.8909 / 6 \mathrm{~N})$ is higher than the other coatings: Ni-P with $(0.72 / 6 \mathrm{~N})$ and $(0.68 / 6 \mathrm{~N})$ for Ni-P-Alumina . For the Ni-P-Carbon coating, the COF kept showing its lead till a load of $10 \mathrm{~N}$ where it became slightly lower than NI-P-Alumina. 


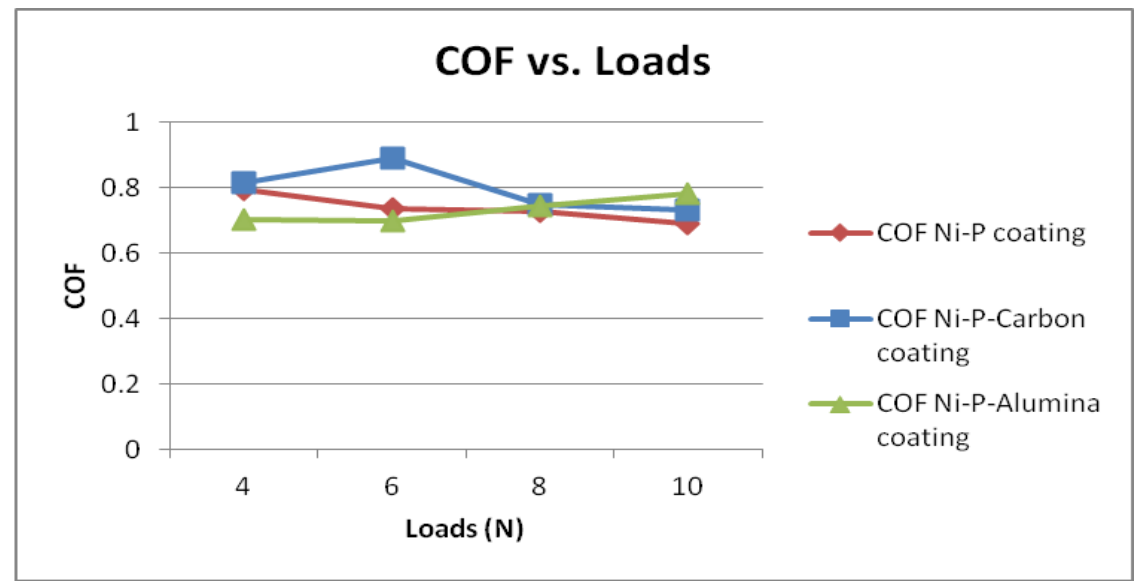

Figure 5. Varition of friction coefficient with respect to applied load.

Curves of mass loss versus various loads $(4,6,8$ and $10 \mathrm{~N})$ for the different tested coatings are shown in Figure 6. The results showed some abnormality, with many ups and downs for the represented samples, this can be due to the abrasive effect of tungsten ball, on the other hand the weight loss of Ni-P-Alumina coating is lower than the other coatings with $0.001 \mathrm{~g} / 4 \mathrm{~N}$ and almost $0 \mathrm{~g} / 6 \mathrm{~N}$ and $8 \mathrm{~N}$, then it increased to $0.0015 / 10 \mathrm{~N}$, which leads to increased wear resistance. That indicates that the behavior of Ni-P-Alumina coating is more resistance compared to the other samples.

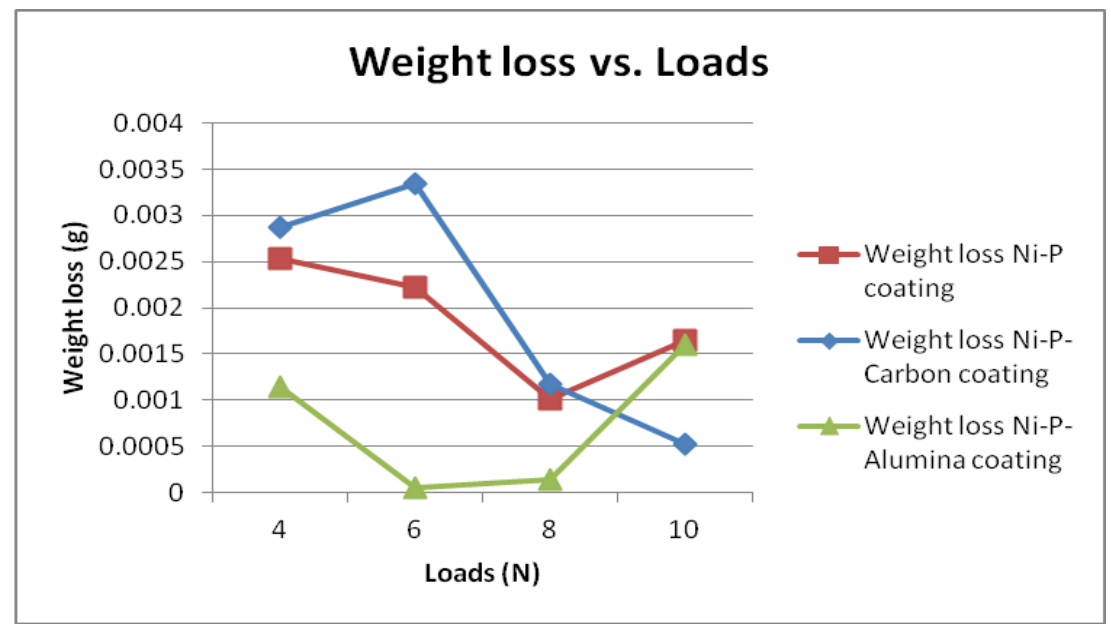

Figure 6. Variation of Weight loss with respect to applied load.

Yet, the descending line of carbon nanotubes from $0.0025 \mathrm{~g} / 4 \mathrm{~N}$ till $0.001 \mathrm{~g} / 8 \mathrm{~N}$ proves that carbon debris can help in lubricating effect which lead to less wear effect with accumulated loads. 


\section{Nano indentation}

Nano indentation is defined as the depth sensing indentation. It is a powerful technique to quantitatively characterize the mechanical properties of small volumes of material to determine the Young modulus, hardness and other mechanical properties. Hardness is a measure of a material's resistance to surface penetration by an indenter with a force applied to it. A prescribed load is applied to an indenter in contact with a specimen. As the load is applied, the depth of penetration is measured. When load is removed from the indenter, the material attempts to regain its original shape, where it will prevented due to the plastic deformation. An analysis of the initial portion of this elastic unloading response can give an estimate of the Young's modulus. In our test, force and depth of penetration are recorded as load is applied from $10 \mathrm{mN}$ to a maximum force of $400 \mathrm{mN}$ and then from the maximum force back to $10 \mathrm{mN}$. A representative force-displacement (penetration depth of indenter) curves showing loading-unloading and different maximum loads range from 10 to $400 \mathrm{mN}$ were obtained using a Berkovich indenter are given in Figure 7.
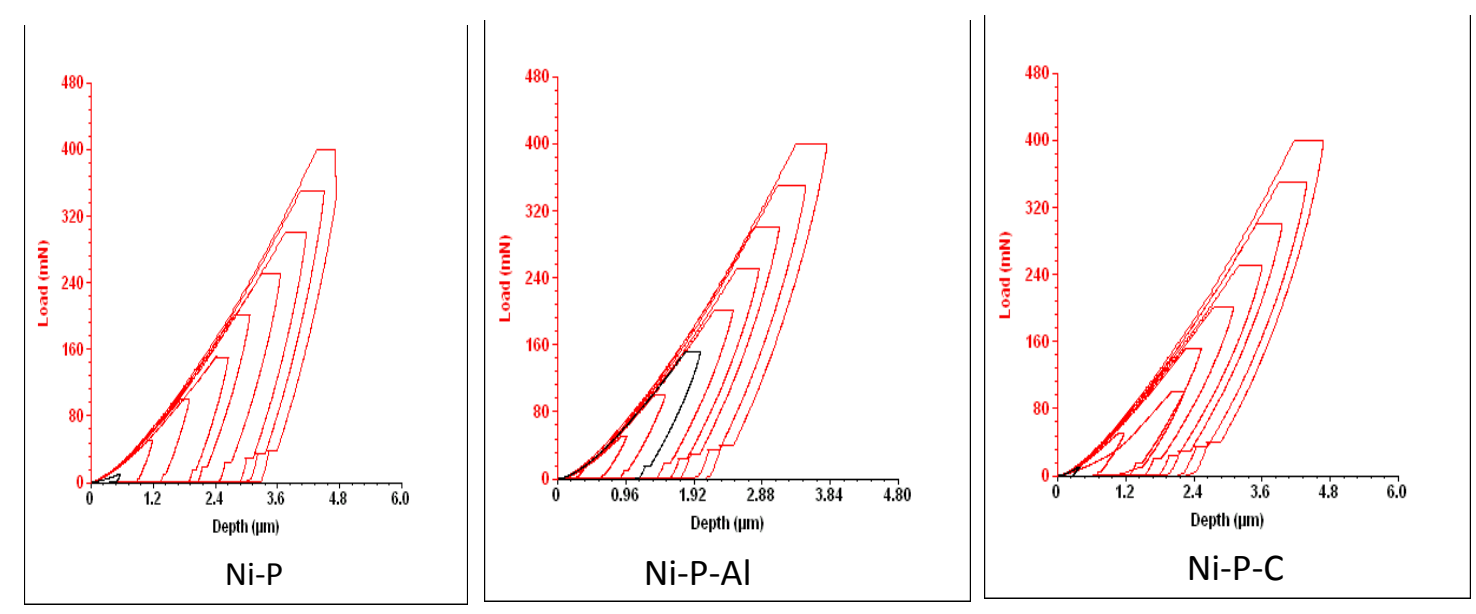

Figure 7. Indentation curves with varying maximum loads.

According to figure 7, the hardness of the samples increases with the composite coating. The Ni-P coating with carbon nanotubes showed be the hardest behaviour with $4.3 \mathrm{GPa}$ at $400 \mathrm{mN}$.

The hardness and Young's modulus tests results are listed in Table 7. The composite coating with Ni-P and Alumina indicates a better hardness with $2.55 \mathrm{GPa}$ compared to the other coatings. The average of elastic modulus is $26.90 \mathrm{GPa}$ for the Ni-P coating, 32.84GPa for the Ni-P-Alumina coating and $20.40 \mathrm{GPa}$ for the Ni-P-Carbon coating. Once again, the highest value is for the Ni-P-Alumina coating. 
Table 7. Hardness and Young modulus results.

\begin{tabular}{|l|l|l|}
\hline Coating & Hardness (Gpa) & Young's modulus (E) (Gpa) \\
\hline Ni-P & 1.32157 & 26.9017 \\
\hline Ni-P-Al & 2.54501 & 32.8446 \\
\hline Ni-P-C & 1.77924 & 20.4004 \\
\hline Ni-P-Ti & 1.5 (using Vicker's) & N/A \\
\hline
\end{tabular}

\section{CONCLUSION}

This Research has proved that even with very small amount of different materials, each type of composite or alloyed coating is obtaining different appearance, thickness and rate of deposition. On the other hand, it showed that composite coating does not give significant corrosion resistance improvement except for alumina where it gives slightly close results to pure Ni-P $1 \mathrm{~h} 30 \mathrm{~min}$. In the case of mechanical properties, carbon nanotubes proved lubrication effect that reduces the wear action especially when the load gets higher and the friction coefficient gets lower, finally, the addition of $\mathrm{Al} 2 \mathrm{O} 3$ to the Ni-P coating resulted in a considerable increase in hardness and a decrease in the COF. Both of these effects were due to the nature of the particles of $\mathrm{Al} 2 \mathrm{O} 3$ and their incorporation in the Ni-P layer, resulting in a more compact layer with smaller grains than the pure $\mathrm{Ni}-\mathrm{P}$ coating.

\section{ACKNOWLEDGEMENTS}

The authors would like to acknowledge the financial support of the National Council for Scientific research (CNRS) in Lebanon, and the help of the Advanced Tribology Laboratory (ATL) in Dalhousie University (Canada).

\section{REFERENCES}

Barker, D. 1993. Electroless Deposition of Metals, Trans. Inst. Metal Finish, 7: 121.

Fields, W. and Zickearf, J. R. 2011. Electroless, Publication of ASM committee on EN platting, Getting Started with Electrochemical Corrosion Measurement. Rev. 1.1, Copyright [1990-2010 Gamry Instruments, Inc].

Lukes, R. 1964. Plating, 51: 969.

Nader, R. Aghadsi M., Farhat Z. and Jarjoura G. 2015. Mechanical and Electrochemical Behaviour of Electroless Nickel Plating on AA6061 Alloy, Journal of Surface Engineered Materials and Advanced Technology. 9(6): 772-775.

Reidel, W. 1997. Electroless Nickel plating, ASN International. 